\title{
SISTEMA DE INFORMAÇÃO GEOGRÁFICA NA IDENTIFICAÇÃ̃ DE CONFLITOS AMBIENTAIS EM ÀREAS DE PRESERVAÇÃO PERMANENTE
}

\section{GEOGRAPHIC INFORMATION SYSTEM IN THE IDENTIFICATION OF ENVIRONMENTAL CONFLICTS IN PERMANENT PRESERVATION AREAS}

\section{Ana Clara de Barros ${ }^{1}$, Tiago José da Silva ${ }^{2}$, Yara Manfrin Garcia $^{3}$, Daiane de Moura Costa ${ }^{2}$, Felipe de Souza Nogueira Tagliarini $^{3}$}

\author{
${ }^{1}$ Faculdade de Ciências Sociais e Agrárias de Itapeva \\ ${ }^{2}$ Universidade Estadual Paulista/UNESP - Sorocaba, SP, Brasil \\ ${ }^{3}$ Faculdade de Ciências Agronômicas UNESP/Botucatu-SP
}

\begin{abstract}
RESUMO
Atualmente, está cada vez mais evidente a necessidade da caracterização e compreensão da organização do espaço e as suas interações com diferentes cenários ambientais e, para isso, é preciso identificar e mapear o estado de uso e ocupação do solo de determinada área, destacando-se assim a utilização dos Sistemas de Informação Geográfica (SIG). Este artigo apresenta a utilização do SIG IDRISI Selva como ferramenta para a identificação e quantificação dos conflitos de uso e ocupação do solo em Áreas de Preservação Permanente na microbacia hidrográfica do córrego da Água Amarela, localizado em Itaberá (SP). Como resultados, enfatiza-se a importância desse tipo de mapeamento para o monitoramento ambiental bem como a preservação da mesma.
\end{abstract}

Palavras-chave: Microbacia hidrográfica. IDRISI. Preservação Ambiental.

\begin{abstract}
Currently, it is increasingly evident the need for characterization and understanding of the organization of space and its interactions with different environmental scenarios and, therefore, is to identify and map the state of land use and occupancy of an area, highlighting so the use of Geographic Information Systems (GIS). This paper presents the use of GIS IDRISI Selva as a tool for identification and quantification of conflicts of use and occupation of land in permanent preservation areas in the catchment of the stream of the Yellow Water, located in Itaberá (SP). As a result, it is emphasized the importance of this type of mapping for environmental monitoring and the preservation thereof.
\end{abstract}

Keywords: Hydrographic watershed. IDRISI. Environmental Conservation. 


\section{INTRODUÇÃO}

O crescimento do número de usuários de Sistemas de Informação Geográfica (SIGs) é um indicador da consolidação da ideia de avançar em direção a uma sociedade informacional. Um dos mais notáveis paradigmas da faceta informacional desta sociedade é a gestão e o domínio da informação territorial (FERREIRA, 2007).

Dangermond (1992) conceituou esses sistemas como um conjunto de hardware, software e dados geográficos projetados eficazmente para contrair, registrar, atualizar, manipular, analisar e visualizar todas as formas de informações geograficamente referenciadas.

Aranoff (1995), em seu entendimento, determinou que os SIGs apresentavam basicamente quatro componentes. O primeiro pertinente aos dados de entrada, como mapas, tabelas, fotos aéreas, gráficos e imagens de satélites, que são transformados de maneira que possam ser utilizados por um SIG. A metodologia segue na geração dos dados que tem destacada relevância, com o intuito de se conseguir um padrão na qualidade nos dados, além do custo e tempo indispensáveis para se finalizar essa etapa.

SIG é mais que um simples automatizador de tarefas existentes, ele favorece um arquivo de dados espaciais na forma original e um instrumento para a exploração de interações entre processos e modelos em fenômenos espaciais e temporais (BURROUGH e MCDONNELL, 1998).

A aparência mais importante no estabelecimento de um SIG, muito funcional e acessível, é a organização do banco de dados. O estágio de montagem do mesmo solicita sérias considerações a respeito dos objetivos a serem conseguidos (DOYLE e GRAY, 1995).

Um SIG pode ser empregado em estudos concernentes ao meio ambiente e recursos naturais, na investigação da previsão de determinados fenômenos ou na ajuda a decisões de planejamento, ponderando a concepção de que os dados armazenados simulam um modelo do mundo real (BURROUGH, 1986).

O IDRISI foi criado na Universidade de Clark, Massachusetts, Estados Unidos da América. Sua primeira versão surgiu em 1987, em uma parceria com a Organização das Nações Unidas (ONU). É um dos aplicativos de Sistema de Informação Geográfica de tipo raster mais empregado no mundo, sendo esta difusão devida as suas grandes capacidades e seu baixo custo (PIROLI, 2010).

O IDRISI reúne ferramentas nas áreas de processamento de imagens, sensoriamento remoto, SIG, geoestatística, apoio à tomada de decisão e análise de imagens geográficas, além disso, o usuário pode desenvolver programas específicos de forma a atender novas aplicações e tem o mesmo, permite a migração de dados para outros softwares (ROSA, 2005).

Esta pesquisa teve como objetivo fazer uso do Sistema de Informação Geográfica, IDRISI Selva como suporte a identificação dos conflitos de uso do solo em Áreas de Preservação Permanente (APPs) na microbacia hidrográfica do córrego da Água Amarela, localizada no município de Itaberá, São Paulo.

\section{MATERIAL E MÉTODOS}

A microbacia hidrográfica do córrego da Água Amarela está inserida no município de Itaberá, região sul/sudoeste do Estado de São Paulo, Brasil (Figura 1). Está situada entre as coordenadas geográficas $49^{\circ} 03^{\prime} 52^{\prime \prime}$ a $49^{\circ} 06^{\prime} 11^{\prime \prime}$ de longitude W Gr. e $23^{\circ} 56^{\prime} 25^{\prime}$ " a $23^{\circ} 59^{\prime}$ 9" de latitude S. A área total da microbacia hidrográfica do córrego da Água Amarela é de 751,84 hectares. 


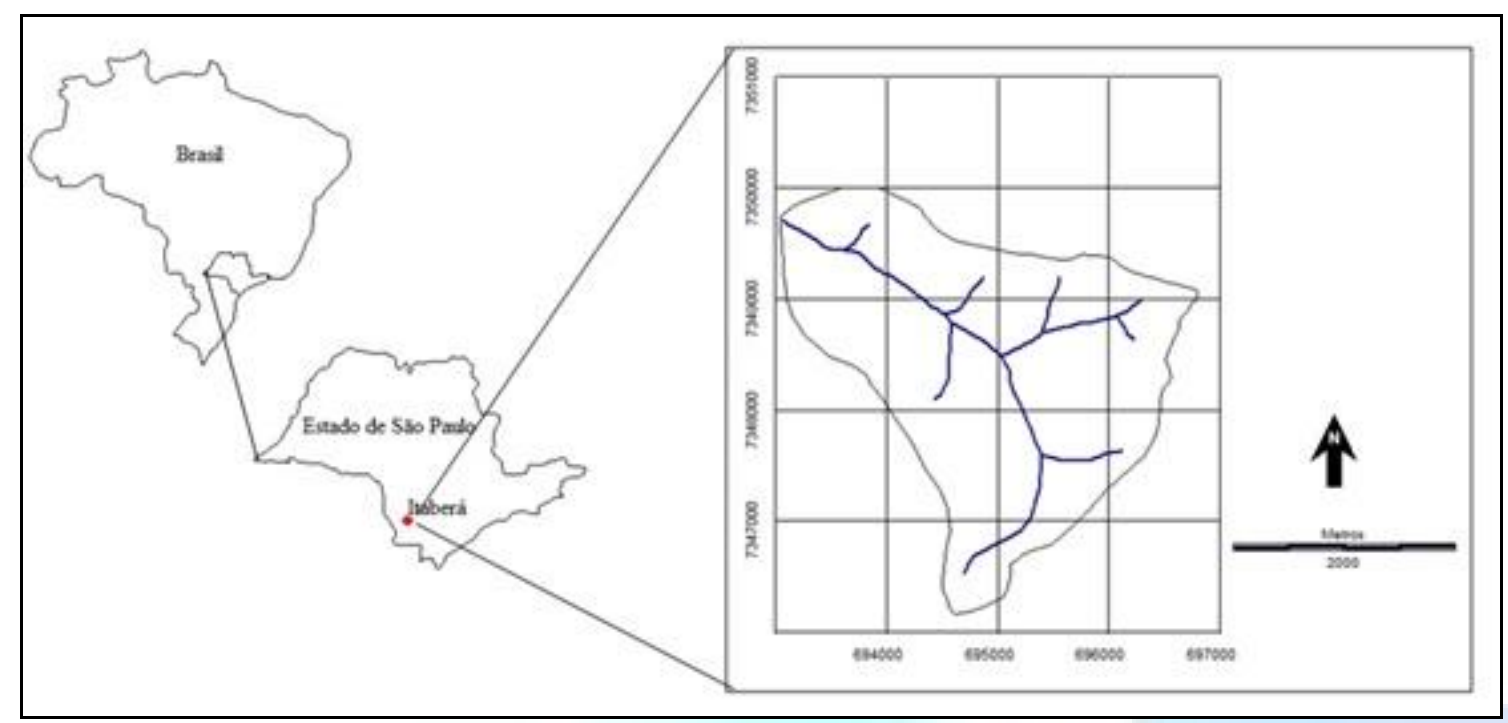

Figura 1. Localização da microbacia hidrográfica do córrego da Água Amarela.

Para a realização desta pesquisa, utilizou-se a carta planialtimétrica do IBGE em formato digital, editada pelo Instituto Brasileiro de Geografia e Estatística - IBGE (1974) referente à folha de Itaberá (SF-22-Z-D-IV-4), escala 1:50.000 com equidistância das curvas de nível de 20 metros.

A imagem de satélite utilizada foi do Landsat - 8, sensor OLI-TIRS (Thermal Infrared Sensor), de dezembro de 2013, da órbita 221, ponto 77, com resolução espacial de 30 x 30 metros, operando em sete bandas espectrais das quais, para este trabalho, utilizaram-se três bandas $(6,5$ e 4$)$ - estas imagens foram obtidas no catálogo de imagens do Departamento do Interior dos EUA/ Pesquisa Geológica (USGS, 2014).

O IDRISI Selva foi usado no processamento das informações, georreferenciamento, composição colorida da imagem de satélite - bandas 6, 5 e 4 em RGB (Red Green Blue), conversão dos dados de vetoriais para raster, elaboração dos mapas de uso e ocupação do solo, geração dos buffers de APPs e os conflitos de uso. Já, o software CartaLinx foi utilizado para a digitalização do limite da área de estudo e rede de drenagem obtidos da carta planialtimétrica do IBGE e as áreas de cobertura vegetal nas imagens de satélite.

O CartaLinx também desenvolvido pela Universidade de Clark se aplica à construção de base de dados relacionais na forma de pontos, linhas e polígonos. Este trabalha com formatos de arquivos vetoriais, porém, tem grande capacidade de importação/exportação de outras extensões. Estes dados são tipicamente exportados para um SIG em coberturas (coverages) (GIANUCA e TAGLIANI, 2012).

A primeira etapa consistiu no georreferenciamento da carta planialtimétrica do IBGE no qual foi realizado no IDRISI, nesta etapa, colocou-se pontos de controle (coordenadas) no qual eram visíveis na carta. Já, no software CartaLinx ocorreu a delimitação dos elementos - limite e rede de drenagem - sendo que, para o limite foi criado polígono, enquanto que, para a rede de drenagem, linhas.

Novamente no SIG IDRISI georreferenciaram-se as bandas 6, 5 e 4, da imagem de satélite também no módulo Reformat/ Resample do SIG IDRISI e teve como base, a carta planialtimétrica georreferenciada no qual, escolheu os pontos homólogos/controle para facilitar este processo.

Esses pontos são feições homólogas facilmente identificáveis (confluência de rios, cruzamento de estradas e outras) tanto na imagem a ser georreferenciada quanto na que apresenta um sistema de referência. Desta forma, é essencial também que os pontos de controle estejam bem distribuídos ao longo da imagem uma vez que o ajuste e a equação do SIG são feitos com base nesta distribuição (GARCIA, 2014). 
Após o georreferenciamento, efetuou-se o recorte das bandas - extraindo assim apenas a área em estudo - e, em seguida, foi realizado o processo de composição da imagem em RGB (Red, Green, Blue).

Na sequência, no CartaLinx foi realizada a interpretação visual em tela, onde as áreas de uso e ocupação foram classificadas sobre a composição colorida, ampliadas em tela para melhor visualização. Posteriormente, foi exportado para o IDRISI e transformado para o formato raster (matriz digital de linha e colunas).

No SIG IDRISI, foram criados os buffers para as Áreas de Preservação Permanente. O termo buffer é definido por Teixeira e Christofoletti (1997), como forma de análise de proximidade onde zonas de uma determinada dimensão são delimitadas em volta de uma feição ou de um elemento geográfico, levando-se em conta um determinado atributo.

Assim, criou-se um raio de 50 metros circulando as áreas das nascentes e um buffer de 30 metros de cada lado da margem na drenagem ao longo do leito do córrego (medidas estas estipuladas, já que a largura dos cursos de água presentes na área estudada são inferiores a 10 metros) resultando na delimitação das APPs. Para a realização desta etapa teve-se como suporte a Legislação Ambiental vigente, mais especificamente, a Lei Florestal $n^{\circ} 12.727$, de 17 de outubro de 2012 (BRASIL, 2012).

Para identificar as áreas de conflitos de uso do solo em Áreas de Preservação Permanentes, utilizou-se a álgebra de mapas realizando uma sobreposição do mapa de uso e ocupação do solo com o mapa das APPs. A sobreposição é a marca registrada dos Sistemas de Informações Geográfica sendo que somente um SIG pode combinar condições que envolvem feições com diferentes geografias (EASTMAN, 1998).

Em seguida, as áreas de ocorrência dos conflitos de acordo com as classes de uso foram devidamente quantificadas. Considerou-se usos conflitantes as áreas cultivadas e ocupadas com outros fins presentes nas APPs das nascentes e cursos d’água.

\section{RESULTADOS E DISCUSSÃO}

Por meio do mapeamento das áreas de uso e ocupação do solo, do ano de 2013, foi possível a identificação de seis (6) classes de uso que são: mata ciliar, pastagem, construções, solo preparado, reflorestamento e cultura (esta classe é representada pelo feijão, milho, soja e trigo), Figura 2.

Avaliando as classes de uso e ocupação do solo como propriedades de atividades antrópicas ou não, e obtendo o percentual das APPs por essas classes, foi possível estabelecer os valores de ocupação das APPs em cada tipo de uso do solo (Tabela 1). Partindo-se do pressuposto de que, conforme a legislação vigente, os valores de conflito de uso do solo em APP deveriam ser igual à zero. 


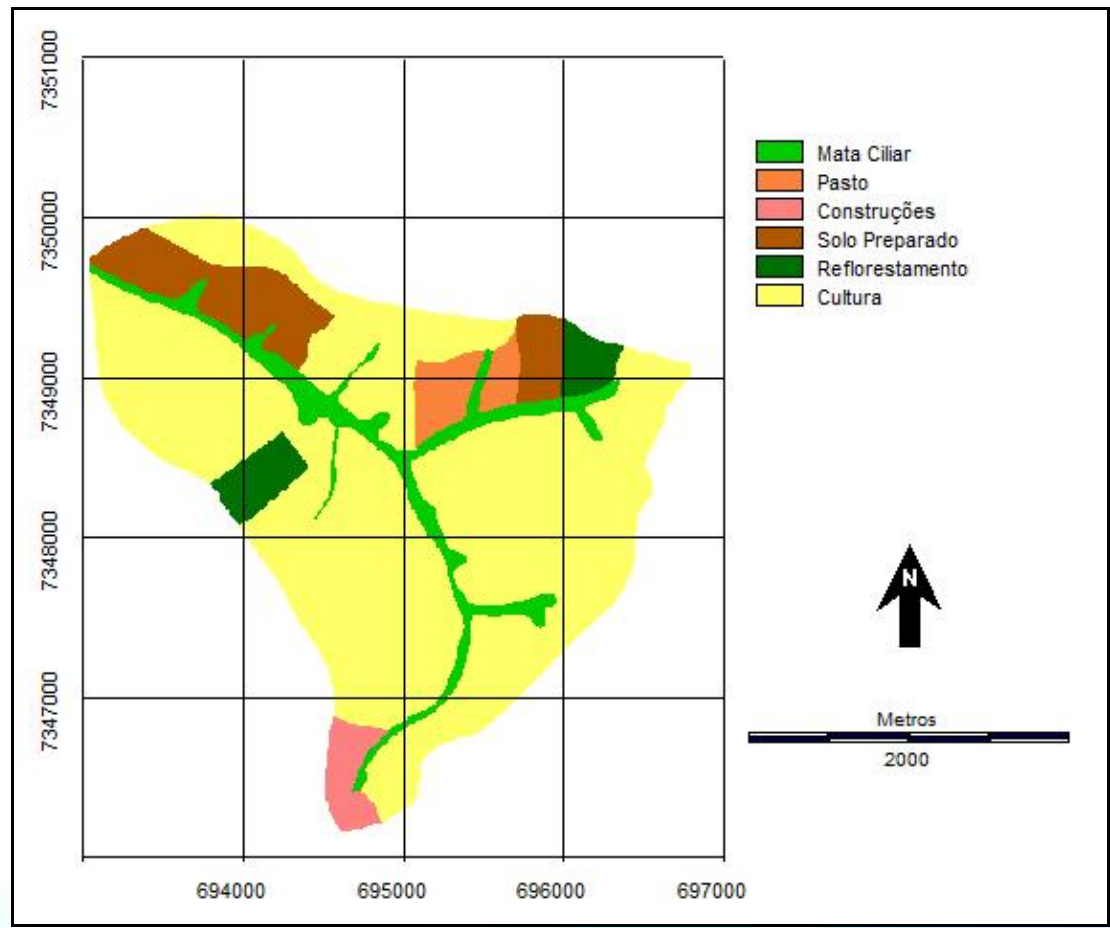

Figura 2. Mapa do uso e ocupação do solo obtido por imagem de satélite

Tabela 1 - Distribuição das áreas e porcentagens de conflitos de uso do solo em APPs.

\begin{tabular}{lcccc}
\hline $\begin{array}{l}\text { Classes de uso } \\
\text { da Terra }\end{array}$ & \multicolumn{2}{c}{ APPs } & \multicolumn{2}{c}{ Conflitos } \\
\hline (ha) & \% & (ha) & \% \\
Mata Ciliar & 38,60 & 61,5 & - & - \\
Pastagem & 0,37 & 0,59 & 0,37 & 1,53 \\
Construções & 1,73 & 2,75 & 1,73 & 7,15 \\
Solo Preparado & 4,06 & 6,47 & 4,06 & 16,80 \\
Reflorestamento & 1,53 & 2,43 & 1,53 & 6,33 \\
Cultura & 16,48 & 26,25 & 16,48 & 68,18 \\
\hline Total & $\mathbf{6 2 , 7 7}$ & $\mathbf{1 0 0}$ & $\mathbf{2 4 , 1 7}$ & $\mathbf{1 0 0}$
\end{tabular}

No que se refere ao uso irregular das APPs, tem-se o predomínio das culturas com 16,48 ha que significa $68,18 \%$ da área, seguida pela classe de solo preparado com 4,06ha (16,80\%). Ressaltase que o solo preparado consequentemente será utilizado também para o plantio de culturas. Analisando dessa forma, seria um total de 20,54 ha $(84,98 \%)$ de área destinada para o plantio de culturas.

Segundo a Resolução CONAMA nº 306, de 5 de julho de 2002, Impacto Ambiental é definido como qualquer alteração das propriedades físicas, químicas e biológicas do meio ambiente, 
causada por qualquer forma de matéria ou energia resultante das atividades humanas que, direta ou indiretamente, afetam a saúde, a segurança e o bem-estar da população, as atividades sociais e econômicas, a biota, as condições estéticas e sanitárias do meio ambiente e a qualidade dos recursos ambientais (BRASIL, 2002). Na Figura 4 é possível identificar alguns desses impactos ambientais.

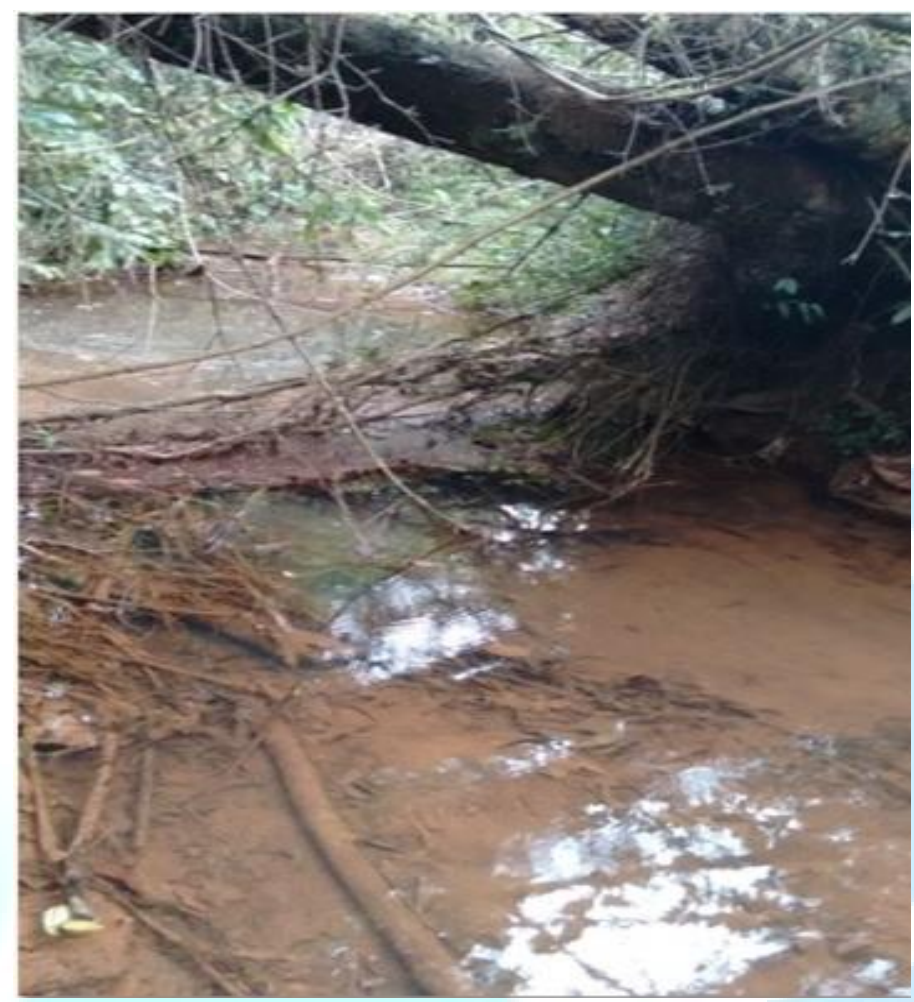

Figura 4. Impactos Ambientais na microbacia em estudo - Assoreamento e queda de árvores na margem do córrego.

\section{CONCLUSÕES}

Por meio do mapeamento das áreas de uso e ocupação do solo, do ano de 2013, foi possível a identificação de seis (6) classes de uso do solo: mata ciliar, pastagem, construções, solo preparado, reflorestamento e cultura (esta classe é representada pelo feijão, milho, soja e trigo). Observa-se que a concentração de áreas de conflito que residem ao longo da margem dos cursos de água da microbacia hidrográfica do córrego da Água Amarela estão causando diversos impactos ambientais como, por exemplo, assoreamento, desbarrancamento das margens dos córregos (ausência da mata ciliar), erosão laminar, entre outros.

\section{REFERÊNCIAS}

ARANOFF, S. Geographic Information Systems: a management perspective. Ottawa: WDL Publications, 1995. 13 pg.

BRASIL, CONAMA, Conselho Nacional do Meio Ambiente. Resolução no 306, de 5 de julho de 2002. Estabelece os requisitos mínimos e o termo de referência para realização de auditorias ambientais. Diário Oficial da União, Brasília, DF, 19 jul. 2002. Disponível em: <http://www.mma.gov.br/port/conama/res/res02/res30602.html>. Acesso em: 19 abr. 2015. 
BRASIL. Lei ${ }^{\circ}$ 12.727, de 17 de outubro de 2012. Diário Oficial da União, Brasília, DF, 18 out. 2012. 2012a. Disponível em: <http://www.planalto.gov.br/ccivil_03/_Ato20112014/2012/Lei/L12727.htm>. Acesso em: 13 abr. 2015.

BURROUGH, P.A. Principles of geographical information systems for land resources assessment. Oxford: Clarendon Press. 1986. 193 p.

BURROUGH, P.A.; MCDONNEL, R.A. Principles of geographical information systems: spacial information systems and geoestatistics. Oxford: Clarendon Press. 1998. 333p.

DANGERMOND, J. What is a Geographic information system (GIS)? In: JOHNSON, A.I; PETTERSSON, C.B.; FULTON, J.L. Geographic Information Systems (GIS) and mapping practices and standards. Philadelphia: ASTM STP 1126, Eds. American society for testing and materials. pp.11-17. 1992.

DOYLE, T.M.; GRAY, N.F. Protocol for monitoring and predicting the impact of acid mine drainage: Designing and setting up a geographical information system (GIS). Thecnical Report: 25, Water Technology Research, Trinity College, University of Dublin, Dublin, 1995. 38p.

EASTMAN, J.R. Idrisi for Windows: Introdução e exercícios tutoriais. Graduate school of geography, Clark University. 1998. 245 pg.

FERREIRA, M. C. Considerações teórica-metodológicas sobre as origens e a inserção do Sistema de Informação Geográfica na Geografia. In: VITTE, A. C. (org.) Contribuições à história e à epistemologia da geografia. RJ: Bertrand Brasil, 2007.

GARCIA, Y.M. Conflitos de uso do solo em APPs na bacia hidrográfica do córrego Barra Seca (Pederneiras/SP) em função da legislação ambiental. 2014, 141 pg. Dissertação (Mestrado em Agronomia/Energia na Agricultura) - Faculdade de Ciências Agronômicas, Universidade Estadual Paulista, Botucatu-SP, UNESP, 2014.

GIANUCA, K.S; TAGLIANI, C.R. Análise em um sistema de informação geográfica (SIG) das alterações na paisagem em ambientes adjacentes a plantios de pínus no Distrito do Estreito, município de São José do Norte, Brasil. Revista da Gestão Costeira Integrada, Rio Grande RS, v.12, n.1, p.43-55, 2012.

IBGE. Instituto Brasileiro de Geografia e Estatística. Carta Topográfica: folha de Itaberá (SF-22Z-D-IV-4). Serviço gráfico do IBGE, 1974. Escala 1:50.000.

PIROLI, E.L. Disciplina de geoprocessamento: Práticas em Idrisi - versão Taiga. Apostila. Universidade Estadual Paulista - UNESP: Campus Experimental de Ourinhos. Ourinhos, 2010, 56p.

ROSA, R. Geotecnologias na Geografia Aplicada. Revista do Departamento de Geografia, v.16, p.81-90, 2005.

TEIXEIRA, A.L.A.; CHRISTOFOLETTI, A. Sistema de informações geográficas: Dicionário ilustrado. São Paulo: Editora Hucitec, 1997. 19 pg. 